\title{
Effect of Aging Heat Treatment on the Microstructure and Creep Properties of the Cast Ni-Based Superalloy at Low Temperature
}

\author{
Xiang-Wei $\mathrm{Li}^{1,2} \cdot \mathrm{Li} \mathrm{Wang}^{1} \cdot$ Xin-Gang Liu ${ }^{1} \cdot$ Yao Wang ${ }^{1} \cdot$ Jia-Sheng Dong ${ }^{1} \cdot$ Lang-Hong Lou $^{1}$
}

Received: 21 June 2018 / Revised: 31 July 2018 / Published online: 27 November 2018

(C) The Chinese Society for Metals and Springer-Verlag GmbH Germany, part of Springer Nature 2018

\begin{abstract}
Effect of aging heat treatment on the grain boundary microstructure and creep properties of a cast Ni-based superalloy was investigated. With increasing aging temperature from 750 to $1000{ }^{\circ} \mathrm{C}, M_{23} \mathrm{C}_{6}$ carbides along the grain boundaries evolve from fine distributed block, continuous film into the coarse discrete block. Moreover, the $M_{23} \mathrm{C}_{6}$ carbides are mainly enveloped within $\gamma^{\prime}$ layers along grain boundaries during $1000{ }^{\circ} \mathrm{C}$ aging. Creep rupture lifetime and elongation at $760{ }^{\circ} \mathrm{C}$ and $645 \mathrm{MPa}$ are improved with increasing the aging temperature. In particular, the creep rupture lifetime of the specimens aging at $1000{ }^{\circ} \mathrm{C}$ is one order of magnitude higher than that of the specimens aging at $750{ }^{\circ} \mathrm{C}$. The enhancement of ductility induced by the $\gamma^{\prime}$ envelopes plays a significant role in the improvement of creep rupture lifetime.
\end{abstract}

Keywords Superalloys $\cdot$ Creep $\cdot$ Grain boundary $\cdot$ Carbides $\cdot$ Aging heat treatment

\section{Introduction}

High-temperature mechanical properties of superalloys are mainly derived from $\gamma^{\prime}$ phase [1-3]. Grain boundary (GB) microstructures, such as carbides and borides, are essential for the realization of the full potential creep properties of polycrystalline superalloys [4-7].

It has been generally reported that $\mathrm{GB} M_{23} \mathrm{C}_{6}$ carbides are beneficial for the improvement of creep properties at elevated temperatures $[4,5,8,9]$. Various reasons have been reported, for example, grain boundary sliding (GBS) is retarded and formation of grain boundary cracks is inhibited [8,9]. Additionally, it has also been suggested that crack propagation rate along grain boundary was effectively reduced by the discrete block GB carbides [10]. Although GBS is one of the major deformation mechanisms in fine-grained wrought and powder metallurgy superalloys during high-temperature creep [11-13], the

Available online at http://link.springer.com/journal/40195

Jia-Sheng Dong

djs@imr.ac.cn

1 Superalloys Division, Institute of Metal Research, Chinese Academy of Sciences, Shenyang 110016, China

2 School of Materials Science and Engineering, University of Science and Technology of China, Hefei 230026, China
GBS shows little effect on the creep deformation of cast superalloys with coarse grains at low temperatures. Thus, the intragranular deformation is considered as the dominated deformation mechanisms for these cast superalloys $[14,15]$. Furthermore, trans-granular failure can occur in cast superalloys during low-temperature and high-stress creep $[16,17]$. Therefore, it is necessary to reveal the role of grain boundary microstructures in the low-temperature and high-stress creep behavior of the cast superalloys.

In addition, it has been recently proposed that the GB precipitates are not $\mathrm{Cr}$-rich $M_{23} \mathrm{C}_{6}$ carbides but $\mathrm{Cr}$-rich borides in the cast superalloys [18-20]. For example, $M_{5} \mathrm{~B}_{3}$ borides have been reported to be formed at the grain boundaries in IN738 and IN 792 superalloys [18, 19]. However, the formation of GB carbides in K417G superalloy has still been observed [21]. It should be also noted that the heat treatments of cast $\mathrm{K} 417 \mathrm{G}$ superalloys were not carried out in the previous studies [21-23]. In fact, the heat treatments have been employed for the newly designed K417G turbine blisks in recent years. Therefore, it is of great significance to examine the effect of aging heat treatment on the microstructure and creep properties of the cast K417G superalloys.

In the present study, solution and aging heat treatments were employed to investigate evolution of the grain boundary microstructures. The effect of GB precipitates on 
creep behavior of the cast $\mathrm{K} 417 \mathrm{G}$ Ni-based superalloy at $760{ }^{\circ} \mathrm{C}$ and $645 \mathrm{MPa}$ was studied.

\section{Experimental}

The chemical composition of a cast Ni-based superalloy $\mathrm{K} 417 \mathrm{G}$ used in this work was listed as follows (in wt\%): $0.17 \mathrm{C}, 9 \mathrm{Cr}, 10 \mathrm{Co}, 3.1 \mathrm{Mo}, 5.4 \mathrm{Al}, 4.3 \mathrm{Ti}, 0.8 \mathrm{~V}, 0.07 \mathrm{Zr}$, $0.015 \mathrm{~B}$ and $\mathrm{Ni}$ (Bal.). The polycrystalline test bars were cast by a vacuum induction furnace. The average grain size of the experimental bars was about $2.8 \mathrm{~mm}$. All the bars were treated by the same elevated temperature solution at $1235{ }^{\circ} \mathrm{C}$ for $3 \mathrm{~h}$ and the first aging treatment at $1080{ }^{\circ} \mathrm{C}$ for $4 \mathrm{~h}$, both followed by air cooling (AC). Then, the secondary aging heat treatments (AHT) were carried out at $750{ }^{\circ} \mathrm{C}, 850^{\circ} \mathrm{C}$ and $1000{ }^{\circ} \mathrm{C}$, respectively, followed by air cooling, as shown in Table 1.

For 3-dimensional (3D) observation of GB precipitates, the specimens under different secondary aging heat treatments were subjected to deep chemically etching in a solution of $17 \mathrm{ml} \mathrm{HNO}_{3}+100 \mathrm{ml} \mathrm{HCl}+7.5 \mathrm{~g} \mathrm{CuCl}_{2-}$ $+7.5 \mathrm{~g} \mathrm{FeCl}_{3}$. For $\gamma^{\prime}$ observation, the specimens were etched electrolytically with a solution of $10 \mathrm{ml} \mathrm{H}_{3} \mathrm{PO}_{4}$ $+90 \mathrm{ml} \mathrm{H}_{2} \mathrm{O}$. The GB microstructures were observed by scanning electron microscopy (SEM). More than 5 SEM micrographs were recorded from the different areas for each sample, and about 100 particles were averaged. The analysis of the grain boundary precipitates was performed on a scanning transmission electron microscopy (STEM). The composition of grain boundary precipitates was determined by using an energy-dispersive spectrometer (EDS).

The test bars treated by the different heat treatments (Table 1) were machined into creep specimens with gauge diameter of $5 \mathrm{~mm}$ and gauge length of $25 \mathrm{~mm}$. The creep tests were carried out under the condition of the applied stress of $645 \mathrm{MPa}$ at $760{ }^{\circ} \mathrm{C}$. The creep machine CSS3905 was used for the creep tests. In addition, two stress-rupture samples were prepared for every heat treatment and the stress-rupture lifetimes were averaged. The fracture surfaces of stress-rupture specimens were examined using SEM.

\section{Results}

\subsection{GB Precipitates in the As-Cast and Solution Heat-Treated Samples}

Figure 1a illustrates SEM images of GB precipitates in the as-cast sample. Further STEM observations of GB precipitates reveal that the fine GB particles are detected to be Cr-riched $M_{23} \mathrm{C}_{6}$ carbides, as shown in Fig. $1 \mathrm{~b}$, c. Similar results have also been observed in the previous study [21]. The formation of $M_{23} \mathrm{C}_{6}$ carbides is suppressed during solution at $1235{ }^{\circ} \mathrm{C}$ followed by air cooling (Fig. 1d).

\subsection{Evolution of GB Precipitates During Aging Heat Treatment}

Formation of $M_{23} \mathrm{C}_{6}$ carbides is not observed during the AHT-1 treatment (Fig. 2a), but fine widely spaced $M_{23} \mathrm{C}_{6}$ carbides precipitate in the AHT-2 samples (Fig. 2b). More fine $M_{23} \mathrm{C}_{6}$ carbides precipitate and grow continuously along grain boundaries after AHT-3 treatment (Fig. 2c). The average size of carbides increases from 0.17 to $0.36 \mu \mathrm{m}$ with increasing the aging temperature from 750 to $850{ }^{\circ} \mathrm{C}$, as indicated in Table 2 . The coarser discrete carbides with about $0.70 \mu \mathrm{m}$ are observed after AHT-4 treatment (Fig. 2d).

Further SEM observations of $\gamma^{\prime}$ reveal that the morphology and size of $\gamma^{\prime}$ inside grain are similar, but morphology of $\gamma^{\prime}$ phase along grain boundaries is different (Fig. 3). Cubic $\gamma^{\prime}$ at grain boundaries is shown in Fig. 3a, b, while a thin $\gamma^{\prime}$ layer forms during the AHT-3 treatment (Fig. 3c). The thickness of the $\gamma^{\prime}$ layer increases, and the $M_{23} \mathrm{C}_{6}$ carbides are mainly enveloped within $\gamma^{\prime}$ layers along grain boundaries after AHT-4 treatment (Fig. 3d). Similar $\gamma^{\prime}$ envelopes were observed in superalloys during long-term thermal exposure [24, 25].

\subsection{Creep property at $760{ }^{\circ} \mathrm{C}$ and $645 \mathrm{MPa}$}

Table 3 shows the average stress-rupture lifetime of the specimens subjected to different heat treatments. The stress-rupture lifetime of the AHT-1 and AHT-2 specimens is very poor, i.e., less than $10 \mathrm{~h}$. The stress-rupture lifetime increased gradually with increasing the secondary aging temperature. The longest stress-rupture lifetime is observed
Table 1 Heat treatment conditions of test bars in the present experiment

\begin{tabular}{lll}
\hline & Solution and first aging heat treatment & Second aging heat treatment \\
\hline AHT-1 & $1235^{\circ} \mathrm{C} / 3 \mathrm{~h}, \mathrm{AC}$ & None \\
AHT-2 & $1080^{\circ} \mathrm{C} / 4 \mathrm{~h}, \mathrm{AC}$ & $750{ }^{\circ} \mathrm{C} / 16 \mathrm{~h}, \mathrm{AC}$ \\
AHT-3 & & $850{ }^{\circ} \mathrm{C} / 16 \mathrm{~h}, \mathrm{AC}$ \\
AHT-4 & & $1000{ }^{\circ} \mathrm{C} / 16 \mathrm{~h}, \mathrm{AC}$ \\
\hline
\end{tabular}



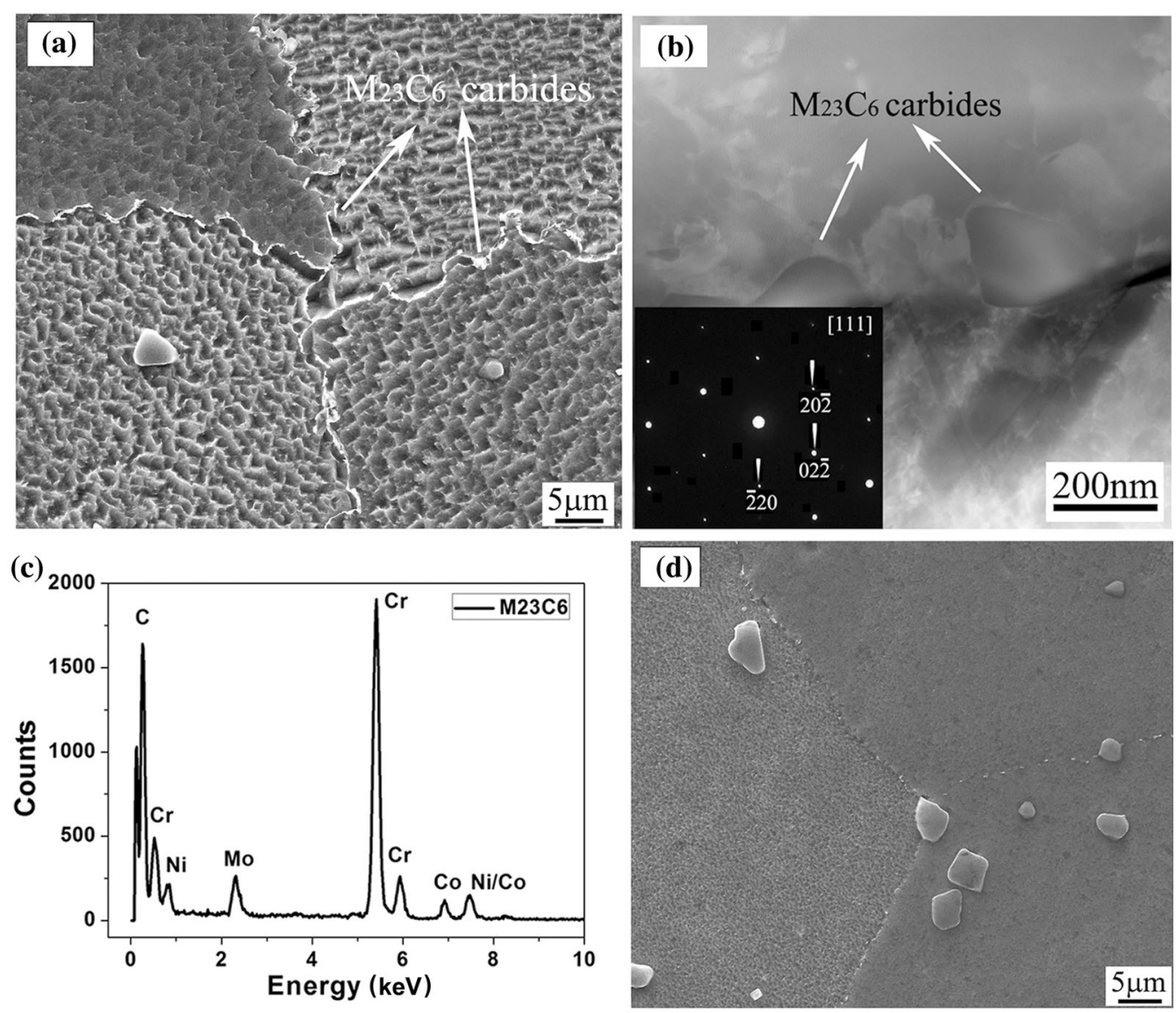

Fig. 1 Morphologies of GB microstructures in the a-c as-cast and $\mathbf{d}$ heat-treated samples: a, $\mathbf{d}$ SEM images of $M_{23} \mathrm{C}_{6}$ carbides, $\mathbf{b}$ STEM images and selected area diffraction pattern of $M_{23} \mathrm{C}_{6}$ carbides, $\mathbf{c}$ composition of $M_{23} \mathrm{C}_{6}$ carbides measured by EDS

in the AHT-4 specimens. In addition, the elongation of stress-rupture specimens is gradually increased (Table 3).

Figure 4 shows the creep curves of the specimens aged at different temperatures. Fracture of the AHT-1 specimen occurs before the completion of the creep stress loading; thus, the creep curve is not illustrated in Fig. 4a. The creep lifetime increases with increasing the aging temperature. In particular, the creep lifetime of the AHT-4 specimen $(138 \mathrm{~h})$ is one order of magnitude higher than that of the AHT-2 specimen $(12 \mathrm{~h})$. The minimum creep strain rates decrease slowly, while the creep rupture strain increases significantly with increasing the aging temperature, as illustrated in Fig. 4b.

Figure 5 shows SEM images of fracture surfaces for the stress-rupture specimens. Two kinds of fracture surfaces, wavy dendrite-like surface and smooth planar surface, are observed in the stress-rupture specimens. The dendrite-like surface is the typical morphology of the intergranular (IG) failure. However, further observation reveals that the area fraction of IG failure increases at first and then decreases with increasing the aging temperature. The area fraction of IG fracture in the AHT-1 and AHT-2 specimens is about $45 \%$ (Fig. 5a, b), and it increases to about $70 \%$ in the AHT-
3 specimen (Fig. 5c). However, the area fraction of IG fracture in the AHT-4 specimen is less than $10 \%$ and transgranular (TG) failure is dominated (Fig. 5d). The dominated failure behaviors in the specimens are transitioned from mixed failure to TG failure with increasing the aging temperature.

Figure 6 shows microstructure of longitudinal section near the rupture surface in the stress-rupture specimens. Continuous cracking along grain boundaries is shown in the AHT-1 specimen (Fig. 6a), while isolated cavities at grain boundaries in the AHT-4 specimen are observed (Fig. 6b).

\section{Discussion}

\subsection{Evolution of GB Precipitates During Heat Treatment}

The GB $M_{23} \mathrm{C}_{6}$ carbides dissolve during the elevated temperature solution. Precipitation of the $\mathrm{GB} M_{23} \mathrm{C}_{6}$ carbides is suppressed during air cooling at a larger cooling rate, as shown in Fig. 1d. The evolution of $M_{23} \mathrm{C}_{6}$ 

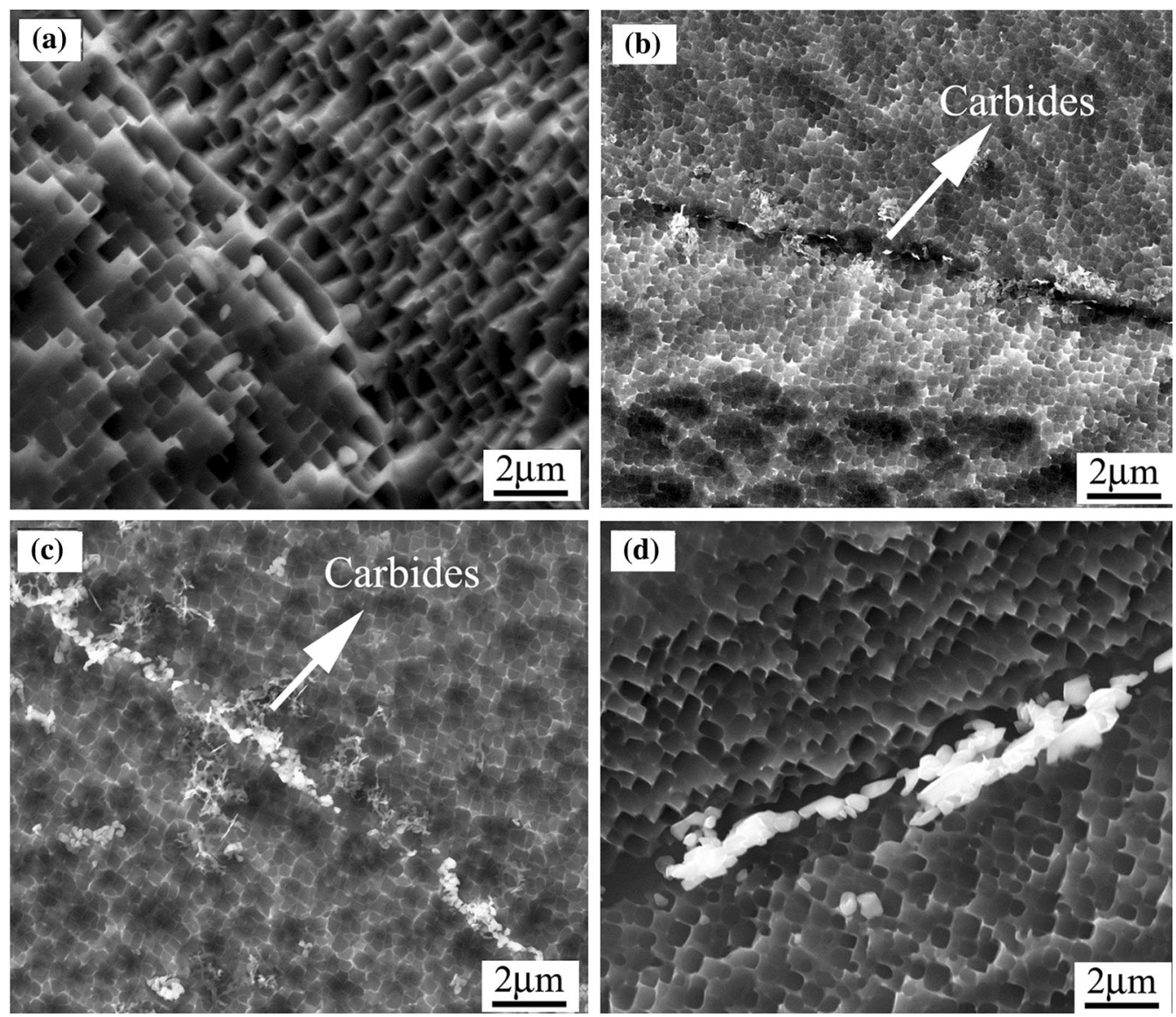

Fig. 2 Secondary electron images of GB $M_{23} \mathrm{C}_{6}$ during aging heat treatments: a AHT-1, b AHT-2, c AHT-3, d AHT-4

Table 2 Average size of $M_{23} \mathrm{C}_{6}$ carbides in the samples with different heat treatment histories

\begin{tabular}{llll}
\hline & AHT-2 & AHT-3 & AHT-4 \\
\hline Average size $(\mu \mathrm{m})$ & $0.17 \pm 0.06$ & $0.36 \pm 0.05$ & $0.70 \pm 0.11$ \\
\hline
\end{tabular}

morphology depends on the aging temperature. Low aging temperature at $750{ }^{\circ} \mathrm{C}$ leads to more carbide nucleation sites but slower growth rate, and fine carbides formed (Table 2). As expected, at intermediate aging temperatures $1000{ }^{\circ} \mathrm{C}$, less nucleation occurs but higher diffusion rate. Therefore, less coarse blocky $M_{23} \mathrm{C}_{6}$ carbides are shown (Fig. 2d).

In general, the formation of the continuous $\gamma^{\prime}$ layer is observed during long-term thermal exposure, which is usually associated with the decomposition of the $M C$ carbides $[24,25]$. In addition, it has been reported that the formation of $\gamma^{\prime}$ envelopes is driven by the boron addition for the reduction of the interfacial energy [26, 27]. In the present work, the precipitation of $\gamma^{\prime}$ layer is favored by the formation of $\mathrm{GB} M_{23} \mathrm{C}_{6}$ during the aging heat treatment. It has been suggested that most of the $M C$ carbides are dissolved during solution treatment, and contents of $\mathrm{C}$ and $\mathrm{Ti}$ in the solution are high. With the formation of $M_{23} \mathrm{C}_{6}$ carbides, especially the coarser $M_{23} \mathrm{C}_{6}$ during aging at $1000{ }^{\circ} \mathrm{C}$, the $\gamma^{\prime}$ layers form near the $M_{23} \mathrm{C}_{6}$ carbides. The reaction, $\mathbf{C}_{\text {solid solution }}+\gamma \rightarrow M_{23} \mathrm{C}_{6}+\gamma^{\prime}$, is operative [28]. Thus, enveloping of carbides within $\gamma^{\prime}$ layers along grain boundaries during $1000{ }^{\circ} \mathrm{C}$ aging can be observed (Fig. 3d).

\subsection{Creep Properties at $760{ }^{\circ} \mathrm{C}$ and $645 \mathrm{MPa}$}

The minimum creep strain rates of the specimens under AHT- 3 and the AHT- 4 treatments are getting closer, while the creep strain increases dramatically, as illustrated in Fig. 7. Therefore, the creep lifetime $\left(t_{\mathrm{f}}\right)$ is associated with the creep strain. The overall strain of creep is expressed in the form as follows $[11,13]$.

$\varepsilon=\varepsilon_{\mathrm{g}}+\varepsilon_{\mathrm{gbs}}+\varepsilon_{\mathrm{diff}}$,

where $\varepsilon_{\mathrm{g}}$ is the strain contributed by intragranular deformation or dislocation slip, $\varepsilon_{\mathrm{gbs}}$ is due to grain boundary sliding, and $\varepsilon_{\text {diff }}$ is induced by the diffusion through the 

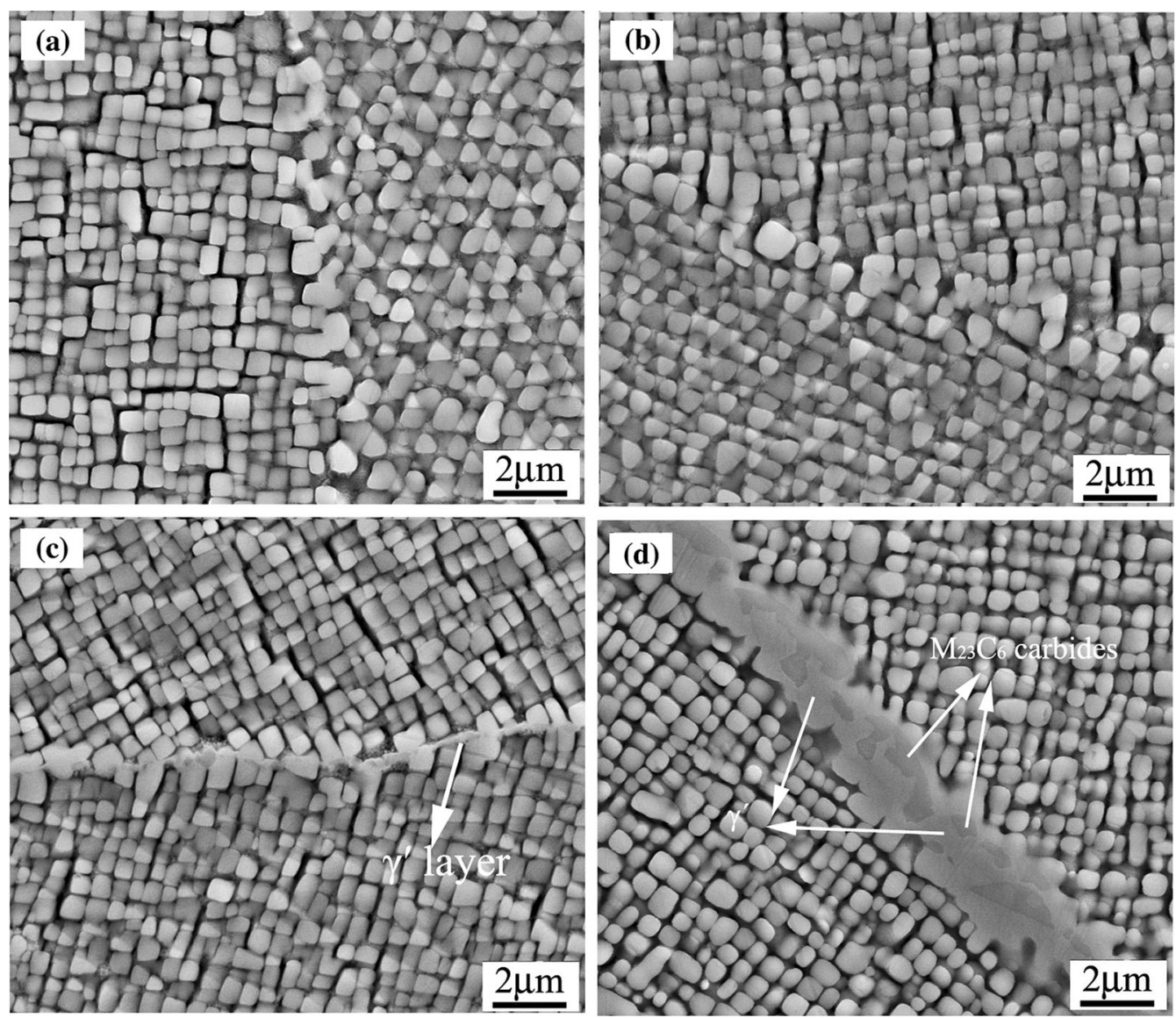

Fig. 3 Secondary electron images of $\gamma^{\prime}$ after different heat treatments: a AHT-1, b AHT-2, c AHT-3, d AHT-4

Table 3 Average stress-rupture lifetime of specimens aged at different heat treatments

\begin{tabular}{lll}
\hline Heat treatments & Average lifetime $(\mathrm{h})$ & Elongation $(\%)$ \\
\hline AHT-1 & $<1$ & $1.8 \pm 1.3$ \\
AHT-2 & $8 \pm 4$ & $2.6 \pm 0.2$ \\
AHT-3 & $40 \pm 9$ & $3.2 \pm 1.0$ \\
AHT-4 & $117 \pm 37$ & $4.2 \pm 0.9$ \\
\hline
\end{tabular}

lattice and along the grain boundaries. Contributions from diffusion creep and grain boundary sliding are negligible during low-temperature and high-stress creep, and intragranular deformation $\left(\varepsilon_{\mathrm{g}}\right)$ becomes dominated $[14,15]$. In addition, it is worthwhile to note that the grain rotation occurs during the intragranular deformation [29-31]. The deformation compatibility among grains is one of the most important factors during the intragranular deformation. In general, the specimens with better deformation compatibility among grains exhibit larger intragranular deformation, and creep strain increases correspondently.
Considering the similar morphology and size of $\gamma^{\prime}$ in the grain of the creep specimens (Fig. 3), the GB precipitates play an important role during the intragranular deformation. The intragranular deformation is prevented by the GB carbides and the minimum creep strain rate is reduced. However, GB carbides act as the sites of microcrack due to local stress concentration during intragranular deformation. Thus, the grain boundary crack and IG failure are observed, as illustrated in Figs. 6a and 5c, respectively. Therefore, the partial increase in the creep lifetime in the AHT-2 and AHT-3 specimens is observed (Fig. 4). It has been suggested that the grain boundary $\gamma^{\prime}$ layer prevents the accumulation of plastic deformation at grain boundary [27]. In this study, the deformation compatibility among grains is improved by the enveloping of carbides within $\gamma^{\prime}$ layer in the AHT-4 specimens. Grain boundary crackings are retarded (Fig. 6b), and the TG failure (Fig. 5d) is observed. Eventually, the time to onset of tertiary creep $\left(t_{t}\right)$ increases, the intragranular deformation becomes larger, and high creep strain and ductility in the specimens at AHT-4 treatment are observed (Fig. 7).

In addition, the specimen at AHT-4 treatment shows a slower increase in the creep strain rate during the tertiary 

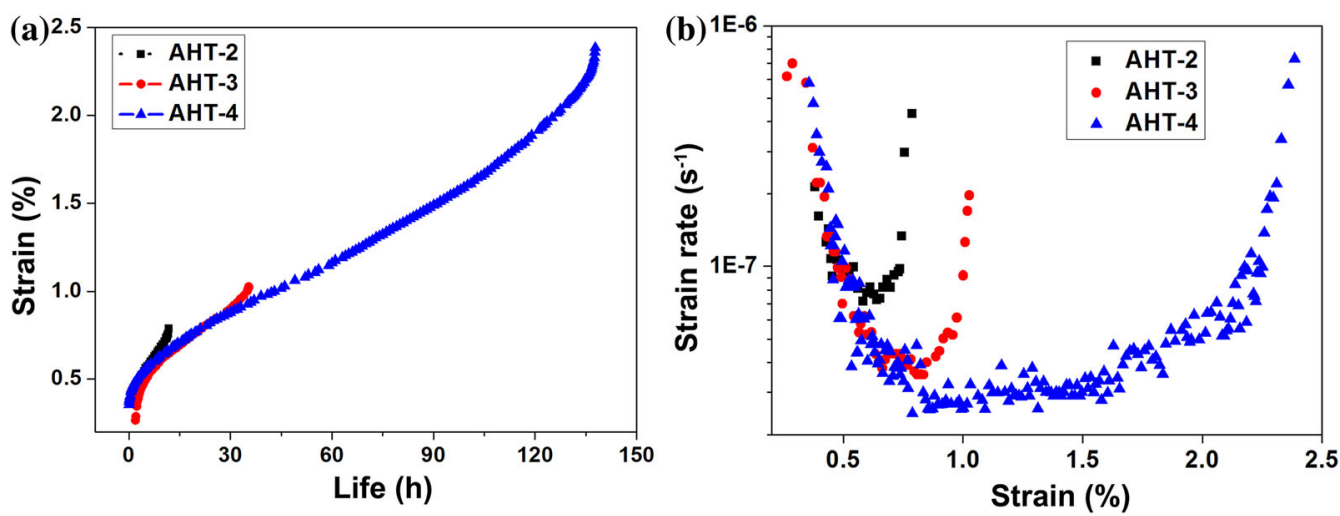

Fig. 4 Creep curves of the specimens with different heat treatments at $760{ }^{\circ} \mathrm{C} / 645 \mathrm{MPa}$ : a creep strain-lifetime curve, b creep strain rate-strain
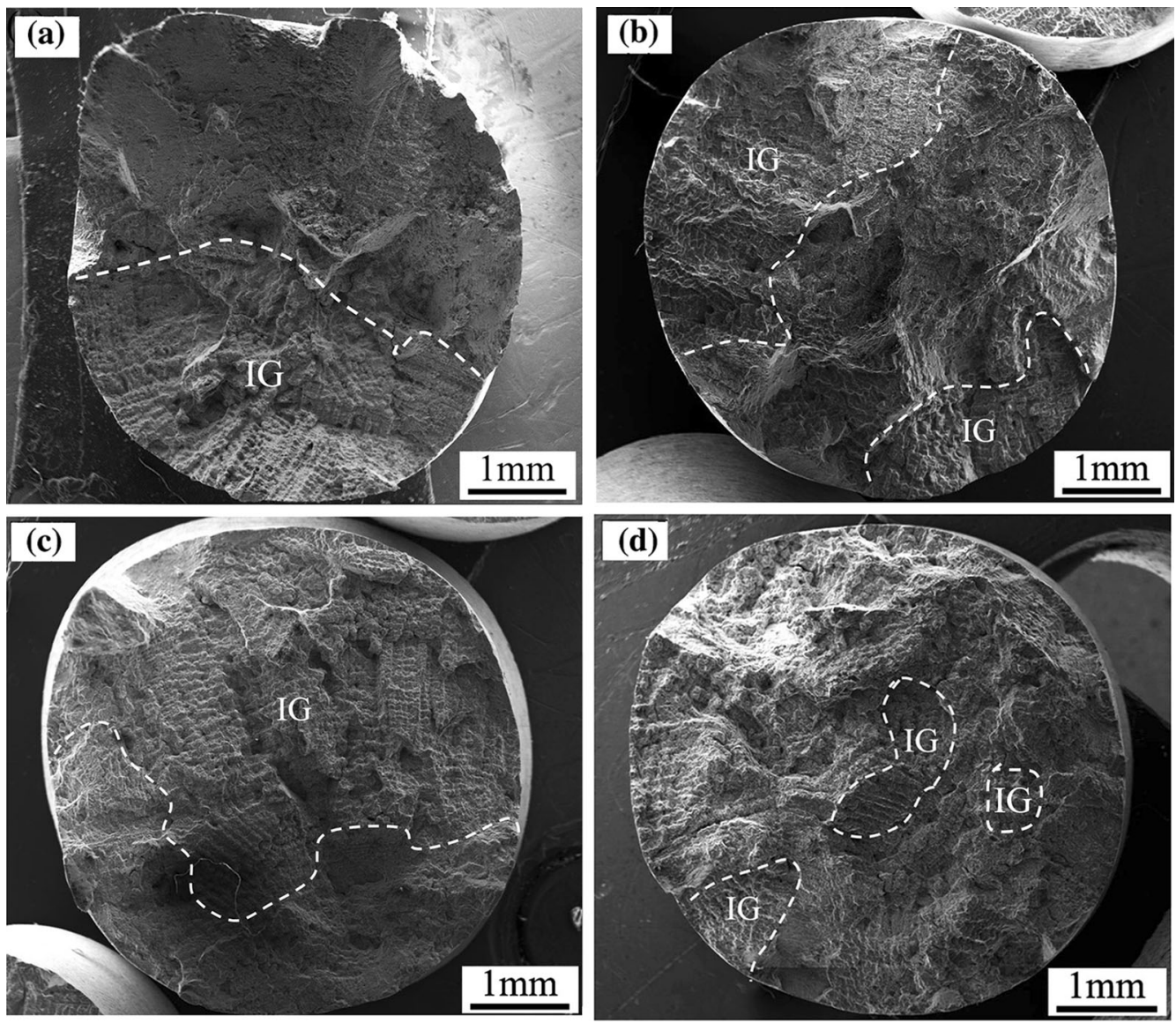

Fig. 5 SEM images of fracture surfaces of specimens tested at $760{ }^{\circ} \mathrm{C}$ and $645 \mathrm{MPa}$ : a AHT-1, b AHT-2, c AHT-3, d AHT-4

creep, as illustrated in Fig. 4b. In general, two kinds of creep damage mechanisms were proposed in previous studies [16, 32]. One of the creep fractures is developed by the grain boundary cavities and cracks $\left(t_{\mathrm{f}} / t_{\mathrm{t}} \approx 1.5\right)$, and the other damage mechanism is derived from the microstructural instability $\left(t_{\mathrm{f}} / t_{\mathrm{t}} \approx 2.5\right)$. The ratio of $t_{\mathrm{f}} / t_{\mathrm{t}}$ reveals (Fig. 8) that the tertiary creep of the AHT-4 specimen is not derived from the grain boundary cracks but from the progressive change of microstructure. The failure behavior obtained from calculation gives a satisfactory agreement with the fracture observation, as shown in Fig. 5. Therefore, the trans-granular failure of the AHT-4 specimen extends the tertiary creep and contributes to the further improvement of the creep life. 

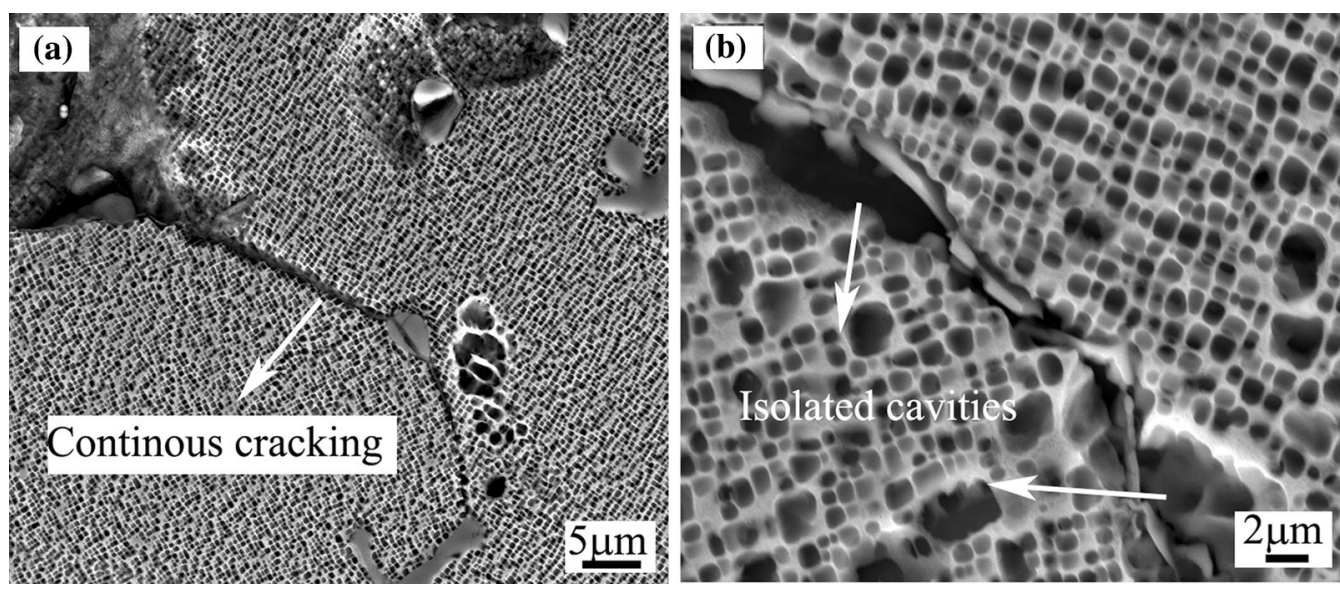

Fig. 6 Images of longitudinal section near the rupture site in the stress-rupture specimens tested at $760{ }^{\circ} \mathrm{C}$ and 645 MPa: a AHT-1, b AHT-4

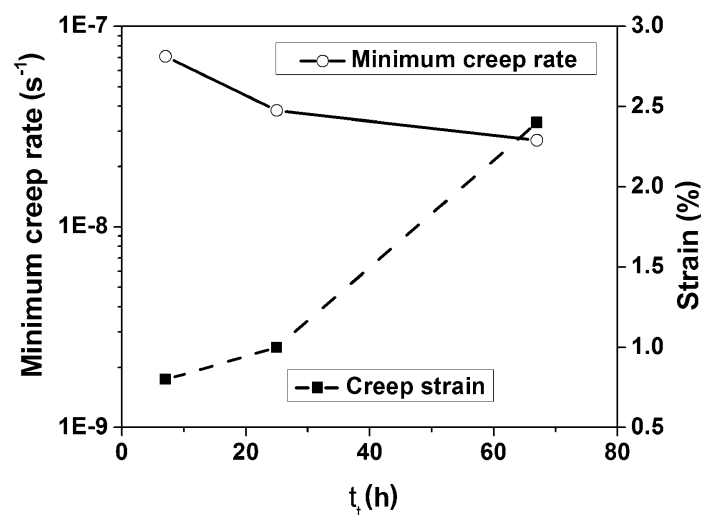

Fig. 7 Relationship among minimum creep rate, creep strain and the time to onset of tertiary creep $\left(t_{\mathrm{t}}\right)$ for the specimens with different heat treatments

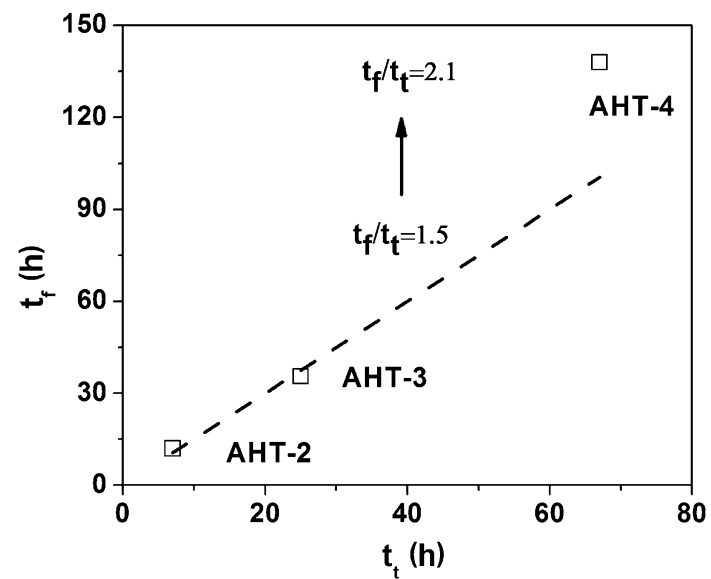

Fig. 8 Relationship between the time to fracture $\left(t_{\mathrm{f}}\right)$ and the time to onset of tertiary creep $\left(t_{\mathrm{t}}\right)$ in the specimens with different heat treatments (the dash line is the fitting line of $t_{\mathrm{f}} / t_{\mathrm{t}}=1.5$ )

\section{Conclusions}

Evolution behavior of GB microstructures during aging heat treatment and its effect on the creep properties at $760{ }^{\circ} \mathrm{C}$ and $645 \mathrm{MPa}$ are investigated in this study. The following conclusions can be given as follows:

(1) Morphology of the GB $M_{23} \mathrm{C}_{6}$ carbides evolves from fine distributed block, continuous film into the coarse discrete block with increasing the aging temperature. Moreover, enveloping of $M_{23} \mathrm{C}_{6}$ carbides within $\gamma^{\prime}$ layers occurs along GB during $1000{ }^{\circ} \mathrm{C}$ aging.

(2) Both the creep lifetime and strain increase gradually with increasing aging temperature. In particular, a markable improvement in the creep rupture lifetime and strain is observed for the $1000{ }^{\circ} \mathrm{C}$ aged specimens.

(3) The enveloping of carbides within $\gamma^{\prime}$ layers plays a significant role in the higher creep strain, which prevents the cracking formation along GB, leading to longer creep lifetime and higher ductility.

(4) Transition of dominated failure mechanisms of the specimen aging at $1000{ }^{\circ} \mathrm{C}$ leads to the further improvement of the creep lifetime for the increasing lifetime of the tertiary creep.

Acknowledgements The work was financially supported by the National Key Research and Development Program of China (No. 2016YFB0701403) and the National Natural Science Foundation of China (Nos. 51701220, 51631008, 51671196 and 51871210).

\section{References}

[1] M.V. Nathal, Metall. Trans. A 18, 1961 (1987)

[2] T. Murakumo, T. Kobayashi, Y. Koizumi, H. Harada, Acta Mater. 52, 3737 (2004)

[3] J.S. Van Sluytman, T.M. Pollock, Acta Mater. 60, 1771 (2012) 
[4] Q.Z. Chen, C.N. Jones, D.M. Knowles, Mater. Sci. Eng. A 385, 402 (2004)

[5] X.M. Dong, X.L. Zhang, K. Du, Y.Z. Zhou, T. Jin, H.Q. Ye, J. Mater. Sci. Technol. 28, 1031 (2012)

[6] P. Kontis, H.A.M. Yusof, S. Pedrazzini, M. Danaie, K.L. Moore, P.A.J. Bagot, M.P. Moody, C.R.M. Grovenor, R.C. Reed, Acta Mater. 103, 688 (2016)

[7] M.Q. Ou, Y.C. Ma, X.C. Hao, B.F. Wan, T. Liang, K. Liu, J. Mater. Sci. Technol. 33, 1300 (2017)

[8] R. Castillo, in Superalloys, ed. by S.D. Antolovich, R.W. Stusrud, R.A. MacKay, D.L. Anton, T. Khan, R.D. Kissinger, D.L. Klarstrom (TMS, Warrendale, 1988), p. 850

[9] X.J. Wu, A.K. Koul, Metall. Mater. Trans. A 26, 905 (1995)

[10] M.J. Donachie, S.J. Donachie, Superalloys: A Technical Guide, 2nd edn. (ASM International Press, Novelty, 2002)

[11] T.G. Langdon, J. Mater. Sci. 41, 597 (2006)

[12] J.L.W. Carter, M.W. Kuper, M.D. Uchic, M.J. Mills, Mater. Sci. Eng. A 605, 127 (2014)

[13] K.X. Dong, C. Yuan, S. Gao, C.L. Jia, J.T. Guo, C.C. Ge, J. Mater. Res. 32, 624 (2017)

[14] M.V. Nathal, R.D. Maier, L.J. Ebert, Metall. Trans. A 13, 1767 (1982)

[15] J.A. Carey, P.M. Sargent, D.R.H. Jones, J. Mater. Sci. 9, 572 (1990)

[16] A. Baldan, J. Mater. Sci. 26, 3409 (1991)

[17] B.N. Du, J.X. Yang, C.Y. Cui, X.F. Sun, Mater. Sci. Eng. A 623, 59 (2015)

[18] H.R. Zhang, O.A. Ojo, M.C. Chaturvedi, Scr. Mater. 58, 167 (2008)
[19] B.N. Du, Z.W. Shi, J.X. Yang, Z.K. Chu, C.Y. Cui, X.F. Sun, L.Y. Sheng, Y.F. Zheng, J. Mater. Sci. Technol. 32, 265 (2016)

[20] P.A.J. Bagot, O.B.W. Silk, J.O. Douglas, S. Pedrazzini, D. Crudden, T.L. Martin, M.C. Hardy, M.P. Moody, R.C. Reed, Acta Mater. 125, 156 (2017)

[21] B.N. Du, Z.Y. Hu, L.Y. Sheng, C.Y. Cui, J.X. Yang, Y.F. Zheng, X.F. Sun, J. Mater. Sci. Technol. 34, 1805 (2018)

[22] L. Gong, B. Chen, Z.H. Du, M.S. Zhang, R.C. Liu, K. Liu, J. Mater. Sci. Technol. 34, 541 (2018)

[23] H. Zhang, Y.C. Wang, F. Liu, S.H. Ai, Q.S. Zang, Z.G. Wang, J. Mater. Sci. Technol. 18, 176 (2002)

[24] X.Z. Qin, J.T. Guo, C. Yuan, C.L. Chen, H.Q. Ye, Metall. Mater. Trans. A 38, 3014 (2007)

[25] X.W. Jiang, D. Wang, G. Xie, H. Li, L.H. Lou, J. Zhang, Metall. Mater. Trans. A 45, 6016 (2014)

[26] B.C. Yan, J. Zhang, L.H. Lou, Mater. Sci. Eng. A 474, 39 (2008)

[27] P. Kontis, E. Alabort, D. Barba, D.M. Collins, A.J. Wilkinson, R.C. Reed, Acta Mater. 124, 489 (2017)

[28] S. Gao, J.S. Hou, K.X. Dong, L.Z. Zhou, Acta Metall. Sin. (Engl. Lett.) 30, 261 (2017)

[29] J.C. Stinville, K. Gallup, T.M. Pollock, Metall. Mater. Trans. A 46, 2516 (2015)

[30] S.H. Zhang, D. Wang, J. Zhang, L.H. Lou, J. Mater. Sci. Technol. 28, 229 (2012)

[31] E. Alabort, D. Barba, S. Sulzer, M. Lissner, N. Petrinic, R.C. Reed, Acta Mater. 151, 377 (2018)

[32] B.F. Dyson, T.B. Gibbons, Acta Metall. Mater. 35, 2355 (1987) 